\title{
Education scholarship: the next step for our specialty
}

\author{
Jonathan Sherbino, MD, MEd
}

$\mathrm{n}$ this issue of $C J E M$, we introduce the first article in a 2-year series focusing on emergency medicine (EM) education. This series attempts to go beyond a traditional understanding of education (e.g., only for physicians in training) and also considers physicians in practice. The goal is to introduce into the EM literature a core series of education topics covering the spectrum of learning. The articles are intended to be accessible, practical and evidencebased. Box 1 lists the topics to be covered. The scope of this series is not intended to be comprehensive; rather, it reflects the triage decisions of the editorial board.

Although the education literature is vast, there are many gaps in the evidence that have been filled by opinion and speculation. The articles in this series will illuminate, at times, the next question(s) that should be investigated. I propose that addressing these education gaps should be the next step for our specialty - EM education

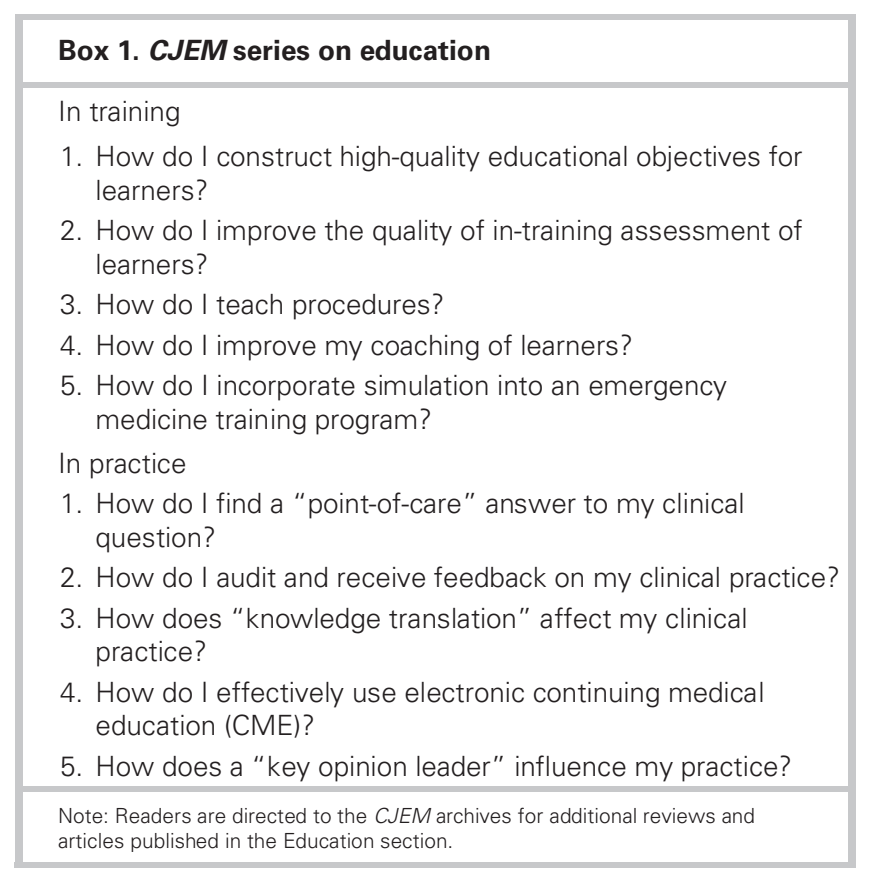

scholarship. Three issues require attention: 1) education innovations are poorly disseminated, resulting in a repetitive reinvention of the "educational wheel," 2) there are important education questions that have not been addressed (and that apply to physicians in practice) and 3) current methodologies, adopted from clinical research, may not answer every question important to education.

\section{SHARE INNOVATIONS}

Scholarship involves the public dissemination of an education innovation that builds on current evidence, theoretical frameworks or best practice. Thus scholarship seeks to move the EM education agenda forward - seeking explanations for the gaps - and counters the isolating silo approach common in education, in which geographical or philosophical neighbours don't share ideas. Poor dissemination of innovations leads to a significant duplication of results (and energy) on low-order priorities at the expense of higher-order questions that require pooled resources. (For example, individually developing a practice examination at each residency program, rather than sharing an examination across many programs, distracts from a national collaboration to develop an EM technical skills curriculum.) As a journal editor, I feel a natural avenue for dissemination is the peer-reviewed manuscript. However, education scholars need not be restricted to this format and may pursue other avenues, including electronic portals (e.g., MedEdPORTAL), wikis, electronic bulletins and communities of practice. Ideally, such dissemination would incorporate a review process ensuring dissemination of best practices and not information overload.

\section{BUILD ON EXISTING BEST PRACTICES}

Scholarship is not simply a synonym for research, but rather encompasses both the investigation of an original

From the Department of Emergency Medicine, McMaster University, and Hamilton General Hospital, Hamilton Ont.

Submitted Apr. 12, 2010; Revised May 10, 2010; Accepted May 15, 2010.

This article has been peer reviewed.

CJEM 2010;12(4):347-8 
question, and the development and improvement of a tool or curriculum based on best practices. Thus scholarship emphasizes that innovations build on the best available evidence or practice.

The theoretical foundation in education is broad and robust, yet many important questions remain. For example, adult learning "theory" still requires the experimental evidence to truly validate it as a theory. Specific to $\mathrm{EM}$, what are the qualities of effective EM teachers? ? $^{2}$ What is the effectiveness of a faculty development program for teaching that is specific to emergency departments? ${ }^{3}$ These questions are being answered, but how do we respond to the gaps unearthed by the questions posed in this series on education? Moreover, what are the education questions facing physicians in practice? The emerging discipline of knowledge translation, a domain of education, raises whole new investigative streams for scholarship. The educational challenges of our specialty require more than simple ad hoc guesses; they require educators to understand and apply the existing evidence and best practices. Where gaps exist, we must seek answers.

\section{EDUCATION INNOVATIONS REOUIRE INNOVATIVE METHODS}

This call for scholarship is not a call for show-and-tell. (We do not need more descriptive reports of a "new" curriculum.) As someone who follows the education literature, it seems to me that there are 3 significant barriers to authentic scholarship: unsophisticated evaluation techniques, methodologic immaturity and inadequate scale. First, much of the scholarship around curricula involves low-level evaluation, essentially reporting the satisfaction of participants in the curriculum. The effectiveness of a curriculum (ultimately, its impact on patient outcomes) is the important marker that should influence the design of educational programs. ${ }^{4} \mathrm{We}$ must move beyond scholarship that reports quality by tallying votes using Web-based survey tools.

Second, evidence-based medicine and the accompanying critical appraisal skills that are essential to our clinical practice of EM have influenced the methodologies of education scholarship. Unfortunately, the methodologic design used to answer whether B-type natriuretic peptide improves clinical outcomes in heart failure does not apply to the question of "How do my peers influence my diagnostic decision-making?" This is not to suggest the educational futility of quantitative methods, but rather to advocate for the parallel development and acceptance of rigorous qualitative methodologic designs. We must descend from the ivory tower of complex statistical analysis of seemingly straightforward clinical questions into the messy swamp populated with important questions that are best answered with new qualitative measures.

Finally, we need to entertain a broader vision of education scholarship that builds a network of centres, pooling resources to ask both more complex questions and discover more generalizable results. The era of underpowered, opportunistic (i.e., reporting of data that is available, yet not necessarily important), one-off programs must come to an end. In its place, we require communities of practice ${ }^{6}$ that share an educational agenda and pool limited resources. Our colleagues in clinical research understand this imperative. The Pediatric Emergency Care Applied Research Network and the Resuscitation Outcomes Consortium are but 2 such examples. Centres of medical education and research are emerging across Canada. The EM community needs to engage these centres and develop our own networks, so that we can answer questions and share innovations particular to our specialty.

This issue of CJEM marks the beginning of a 2-year series on education that the editorial board anticipates will spark debate. I hope that the ensuing discussion invigorates EM education scholarship. The progression of our specialty requires tools and curricula founded on best evidence and best practice.

\section{Competing interests: None declared.}

Keywords: education, scholarship, research

\section{REFERENCES}

1. Knowles M. The modern practice of adult education. San Francisco (CA): Jossey-Bass; 1980.

2. Bandiera $G$, Lee $S$, Tiberius R. Creating effective learning in today's emergency departments: how accomplished teachers get it done. Ann Emerg Med 2005;45:253-61.

3. Sherbino J, Frank J, Lee C, et al. Evaluating "ED STAT!": a novel and effective faculty development program to improve emergency department teaching. Acad Emerg Med 2006;13: 1062-9.

4. Kirkpatrick D. Evaluating training programs: the four levels. San Francisco (CA): Berrett-Koehler; 1994.

5. Schon D. Educating the reflective practitioner: toward a new design for teaching and learning in the professions. San Francisco (CA): John Wiley \& Sons; 1987.

6. Wenger EC, Snyder WM. Communities of practice: the organizational frontier. Harv Bus Rev 2000;78:139-44.

Correspondence to: Dr. Jonathan Sherbino, Department of Emergency Medicine, Hamilton General Hospital, 237 Barton St. E., Hamilton ON L8L 2X2; sherbino@mcmaster.ca 